Investigaciones Fenomenológicas, vol. Monográfico 7, 2018, 129-150 e-ISSN: $1885-1088$

\title{
Embree and Cairns on Phenomenology and Psychology
}

\author{
EMBREE Y CAIRNS SOBRE FENOMENOLOGIA Y PSICOLOGÍA
}

\author{
Michael Barber \\ Saint Louis University, Misuri \\ barbermd@slu.edu
}

\begin{abstract}
This article compares and contrasts Dorion Cairn's treatment of the relationship between phenomenology and psychology with Embree's handling of that same topic. Embree, who to a great degree aligns with Schutz, and Cairns converge on the treatment of behaviorism. However, fundamental differences appear in their contrasting approaches to psychology, with Cairns seeking to uphold the distinctiveness of philosophy/phenomenology over against psychology and Embree/Schutz inclining toward a more collaborative engagement with psychology. Their differences reflect their preference for transcendental philosophy or phenomenological psychology, both of which possible preferences were clearly recognized by Edmund Husserl in his "Nachwort zu meinen Ideen". These preferences in turn have to do with the ultimate philosophical purposes each author is pursuing.
\end{abstract}

Keywords:Transcendental phenomenology. Phenomenological psychology. Theory of science. Methodology. Cultural sciences. Behaviorism.
Resumen: Este artículo compara y contrasta el tratamiento de Dorion Cairn de la relación entre fenomenología y psicología con el manejo por parte de Embree del mismo tema. Embree -que en gran medida se alinea con Schutz- y Cairns convergen en el tratamiento del conductismo. Sin embargo, las diferencias fundamentales aparecen en sus enfoques que contrastan con la psicología, con Cairns tratando de mantener el carácter distintivo de la filosofía / fenomenología frente a la psicología y con Embree/Schutz inclinándose hacia un compromiso más colaborativo con la psicología. Sus diferencias reflejan sus preferencias por la filosofía trascendental o por la psicología fenomenológica - ambas preferencias posibles fueron claramente reconocidas por Edmund Husserl en su "Nachwort zu meinen Ideen". Estas preferencias a su vez tienen que ver con los propósitos filosóficos finales que persigue cada autor.

Palabras clave: Fenomenología trascendental. Psicología fenomenológica. Teoría de la ciencia. Metodología. Ciencias culturales. Conductismo. 


\section{INTRODUCTION}

In recent years, Lester Embree produced two significant monographs: The Schutzian Theory of the Cultural Sciences (Dordrecht, Springer, 2015) and Reflective Analysis: A First Introduction into Phenomenological Investigation (Morelia, Editorial jitanjáfora, 2003). These books reflect two fundamental philosophical interests of Embree: theory of science (or Wissenschaftslehre) and the basic doing of phenomenology, as opposed to studying the texts of phenomenological authors (Embree 2003, 10). At the same time, Embree, along with Richard Zaner and Fred Kersten, had been publishing articles found in the Dorion Cairns Archives, and coming out, in particular, with a monograph, Cairns's dissertation, The Philosophy of Edmund Husserl (Dordrecht, Springer, 2013), and a collection of essays by Embree entitled Animism, Adumbration, Willing, and Wisdom: Studies in the Phenomenology of Dorion Cairns (Bucharest, Zetabooks, 2012). Embree repeatedly praised Cairns as his teacher, to whom he dedicated Reflective Analysis. Indeed, several of the themes Embree addresses in Reflective Analysis reflect subjects that Cairns addressed in depth, such as the need to engage in the doing of phenomenology rather than scholarship on it; the emphasis on knowing, valuing, and willing; the focus on "intentiveness" for which he credit Cairns; the recognition of the importance of culture and secondary passivity; the repeated discussion of feigning; the highlighting of perceptual "appearances"; and the distinguishing between direct and indirect experiencing (Embree 2003, 10, 20, 40, 112, 120, 136, 140, 188, 200, 314, 328, 354-356, $384,390,428,452,458,502,528)$. Reflective Analysis shows the influence of Cairns on Embree, and it is no wonder that Embree dedicated the book to him. But what of the theory of science, Embree's other predominate interest? At first, one might think, as I did, that it was basically Schutz's influence that lies at the root of this concern of Embree's and that Cairns's work has nothing to do with the theory of science, but the fact is that Cairns was quite interested in the relationship between phenomenology and psychology, and, in fact, for the first half of his career at Hunter College in New York and Rockford College in Illinois, he taught psychology (Cairns 2002b, 69).

This article will compare and contrast Cairn's treatment of the relationship between phenomenology and psychology with Embree's handling of that same topic. What will become apparent is that although Embree, who to a great degree 
aligns with Schutz, and Cairns converge on the treatment of behaviorism, fundamental differences appear in their approach to psychology, with Cairns seeking to uphold the distinctiveness of philosophy/phenomenology over against psychology and Embree/Schutz inclining toward a more collaborative engagement with psychology. Their differences reflect their preference for transcendental philosophy or phenomenological psychology, both of which possible preferences were clearly recognized by Edmund Husserl in his "Nachwort zu meinen Ideen".

\section{CAIRNS ON THE RELATIONSHIP BETWEEN PSYCHOLOGY AND PHILOSOPHY}

In 1934, Cairns was lecturing at the New School on Husserlian phenomenology, and he took issue with Dr. Andrew D. Osborn's interpretation of Husserl's thought, as is indicated in what appears in Cairns's papers to be the beginnings of a review of Osborn's 1934 The Philosophy of Edmund Husserl in its Development from his Mathematical Interests to his First Concept of Phenomenology in Logical Investigations. In that fragment, Cairns insists that Husserl's Ideen introduced a development beyond Logical Investigations in contrast to Osborn's belief that the later work merely restates the earlier one ${ }^{1}$

Cairns (2002a, 45) understood the Logical Investigations to involve the adoption of an attitude of suspended judgement toward things given in experience (to avoid taking over unreflectively prejudices about such things) and an attempt to describe the structure of awareness of objects and its typical ways of meaning objects (such as in the "present" or "future" or as "physical" or "cultural"). At this early stage of Husserl's work, the term "phenomenology" referred merely to the careful descriptions of things, that is, what appeared in experience exactly as they appeared (Cairns 2007, 117). However, in Cairns's view, Husserl's account of the structure of awareness to which objects were

\footnotetext{
1 "Dr. Osborn's monograph presents for the first time in English an abstract of Husserl's Logische Untersuchungen. He has strictly limited his theme to the development of Husserl's thought up to the publication of the first edition of that work and accordingly it may be of interest to consider what the position of that work is in the light of his later work. This is particularly desirable because Dr. Osborn is in error when he states that the Ideen 'is in essence a restatement of the main points of Logical Investigations' and that 'the understanding of it is greatly helped by approaching it through the earlier work.' Indeed, it is not too much to state that to approach the later works armed with concepts gathered from the first edition of the Logische Untersuchungen is to render an understanding of phenomenology more difficult than it would be if one came empty-handed". Cairns 2002a, 43.
} 
given, for all its rigor, seemed to be nothing more than a kind of introspective psychology. Consequently, the Investigations seemed to depend upon results arrived at through psychological research. This reliance, however, was problematic since the Investigations argued that logic should not be based on psychology, under pains of falling into psychologism. Paradoxically, Husserl's nonpsychologistic logic rested on an informally articulated introspective psycho-logy (Cairns 2002a, 47).

In fact, Husserl specifically described the first edition of Logische Untersuchungen as a "descriptive psychology"-a statement he retracted two years later. Despite that retraction, the way he presented the first edition was thoroughly consistent with his earlier work, such as the Philosophie der Arithmetik, which he subtitled "Logical and Psychological Investigations". The fact that he always regarded the investigations of the Arithmetik as "phenomenological" (even though he subtitled them as "psychological") indicates that he did not draw clearly the distinction between phenomenology and psychology that he was only able to make definitively in the 1920s (Cairns 2007, 118).

An additional problem for the early Husserl in Cairn's opinion was that within a purely descriptive psychology there are various presuppositions on which one relies and about which one has not yet become sufficiently critical. For instance (Cairns 2002a, 47), psychological descriptions of awareness have as their themes a mind believed without sufficient examination to exist in world time. Such a mind would also be the mind of a psycho-physical object, a mind connected with a body, and, consequently, such a mind is taken as developing in the natural world from birth, as a process in world time. In his letter to John Wilde, Cairns (1975, 160) shows how Husserl himself in his later works (Formal and Transcendental Logic and "Nachwort zu meinem Ideen") criticized his early work similarly, for not being sufficiently critical of suppositions. In the later works, Husserl acknowledges that the judgments produced by a "pure psychology" might focus only on inner processes and seek to establish their essential characteristics. However such judgments would still involve a co-positing of the relationship of such psychic processes to the organism and therefore to something worldly, even though this co-positing might not enter expressly into the conceptual content of the judging. Such a co-positing would still have its determining effect on those judgments unless this co-positing is consciously bracketed. Furthermore, Cairns (ib. 162) notes how the later Husserl described 
his earlier Philosophy as Rigorous Science as a descriptive psychology focusing on inner processes and excluding (via "pure psychological reduction") any relationship with physical processes, that is, as a natural fact. However, the later Husserl recognized that such a psychology would nevertheless still consider psychic processes as worldly beings; such descriptive psychology only refrains from conceptually relating this worldliness to physical nature (ib. 163f). Thus, even a pure psychology deploying an eidetic methodology aimed at delineating essential features does not prescind from the supposition of the worldliness of the objects whose essences it seeks to determine, and, insofar as a pure eidetic psychology is conducted within the natural attitude it remains a dogmatic, positive science despite its a priori nature (ib. 165).

According to Cairns (ib. 161), following Husserl, the question comes down to what one wants for philosophy, especially since ideally, it ought not itself be a positive science and it ought not base itself on such positive sciences as psychology or anthropology. Husserl argued that to base one's philosophy on a positive science of man or the human psyche is to succumb to a form of psychologism, "corrupts the pure meaning of philosophy". Cairns (ib. 161) cites Husserl in a passage from "Nachwort zu meinen Ideen" that reiterates the danger to philosophy if it is based on psychology:

The misdirectedness remains unaltered even when a pure inner psychology is developed as an a priori science. Even then, pure inner psychology remains a "positive" science and can be the basis for "positive" or "dogmatic" science-but never for philosophy. (Cairns's translation of Husserl 1952, 148)

There are two ways in which psychologism "corrupts" philosophy. Husserl (2001, 1, 77-83, 90-99, 119-122, 129-133), in the "Prolegomena" to the Logical Investigation, illuminated psychologism's basic flaw. The psychologistic explanation of the a priori rules of logic (e.g., the principle of contradiction) as merely the causal products of a particular empirical, material context in the end relativizes those rules to that context, as if other material, causal processes might have yielded an alternative set of logical rules, in which, for example, the principle of contradiction would no longer hold. Psychology and the very structure of explanation itself, however, both cannot dispense with the principle of contradiction insofar as both depend upon claims whose terms must mean one thing and not another if those claims are to have any clear meaning at all and 
insofar as those claims present themselves as true and not false. Moreover, if the account of the mental acts in relation to which objects (real or ideal) were given would itself depend ultimately on explanations given by psychological science, those claims would be vulnerable to being undermined should the psychology upon which they depend be disproven. In addition, if mental acts are construed as the products of particular, context-limited empirical, material processes-as psychological science would do-then could not the mental acts of philosophy itself, e.g. the knowing and describing of other mental acts such as "perception", "memory", and others be themselves also relativized to their causal context in such a way that this knowing and describing could make no claim to the universality to which philosophy has aspired? To base philosophical claims on the findings of contemporary psychological or anthropological science risks relativizing those claims themselves to the current state of that science or to the material causal forces on which empirical science focuses.

But for Cairns and for Husserl, another problem with psychologism has to do with how it falls short of the conscientiousness requisite for philosophy, thereby "corrupting" philosophy, to use Cairns's translation of Husserl. While the "Prolegomena" denies the psychological explanation of the rules of logic, the "objects" correlative to psychological acts, Husserl's descriptive psychological account of those acts, while "reflective", nevertheless tends simply to take over common sense or even theoretical psychological findings of those acts without rigorous philosophical examination, without submitting to scrutiny their unexam-ined worldly presuppositions. As such, this descriptive psychological account does not meet the standard for philosophy that Husserl articulates in his Cartesian Meditations, the text of Husserl that Cairns $(2002 a, 48)$ considered to be the most clear and comprehensive account of the purpose and method of transcendental awareness. For Cairns, the Cartesian Meditations clarified what he took to be the more primitive analyses of Ideen, which had at least introduced the idea of the phenomenological reduction and the opening of the transcendental sphere. Philosophy for Husserl involves striving for complete freedom from prejudices, "shaping itself with actual autonomy according to ultimate evidences it has itself produced" (Husserl 1960,6) arriving at a knowledge for which the philosopher "can answer from the beginning, and at each step, by virtue of his absolute insight" (ib. 2). Hence, one could take over any description of mental 
acts developed by a descriptive psychology only if one has "seen for oneself" that those descriptions validly, or fulfillingly, presented such mental acts.

Cairns $(2004,26)$ articulated a similar vision of philosophical rigor:

The fundamental methodological principle of Husserlian phenomenology may, I think, be initially formulated as follows: No opinion is to be accepted as philosophical knowledge unless it is seen to be adequately established by observation of what is seen as itself given "in person". Any belief seen to be incompatible with what is seen to be itself given is to be rejected. (italics are Cairns's)

Such a view of philosophy requires a critical stance toward the worldly presuppositions that Cairns thought that the psychologistic positions of Philosophy as Rigorous Science had not subjected to sufficient scrutiny. Consequently, the attitude of neutrality or self-restraint that characterizes the transcendental reduction that the Husserlian phenomenologist takes up

[...] means not only that he makes explicit and seizes upon the believedness of the continuously, even if "only tacitly", automatically, believed in intentionally objective world as a whole, but also that he actively dissociates himself from this fundamental and continuously validated belief. Thus the world and all intra-worldly things, in the broadest sense, are regarded purely as "what is believed-in", "what is meant", etc. This fixed policy of dissociation from all believing, valuing, and willing -automatic as well as actional- is then maintained in his reflective seizing upon mental processes. (ib. 35 , his italics)

One's mental life itself now becomes a process in the world correlative to one's transcendental life, which presupposes neither the existence nor the possibility of the world, as other all other philosophical inquiries do, at least tacitly (ib. 35f).

One can see finally why Cairns opposed Osborn's view that Logical Investigations was Husserl's fundamental work whose findings subsequent works only restated. While Husserl recognized in the Investigations that the norms of logic could not be psychologically explained, he nevertheless relied on a descriptive psychology that would have rendered philosophy itself as dependent upon a positive science and would have fallen short of the standards of philosophy that require that one not accept any descriptions that one has not rigorously examined and seen for oneself as true. The introduction of the phenomenological reduction in Ideas 1 made it imperative that descriptions of acts and their correlative 
objects need to be scrutinized from within the framework the reduction opens, namely the sphere of transcendental philosophy. While Cairns recognizes that the Ideas and Philosophy as Rigorous Science initiated this transition to the transcendental sphere, he saw the later works of Cartesian Meditations and Formal and Transcendental Logic as achieving a kind of culmination of the transition begun in those earlier works. Paradoxically, these later works bring to conclusion the critique of psychologism that had begun in the "Prolegomena" to the Logical Investigations but that had not been adequately executed in that Husserl relied on an insufficiently examined descriptive psychology in that earlier work. It is clear, too, why Cairns asserted that not only do the later works not merely restate the results of the Investigations but it is also the case that one cannot really understand the achievement and the limitations of the Investigations unless one views them from the perspective of Husserl's later works.

In a sense, Cairns's engagement with psychology results in a kind of Wissenschaftslehre in which psychology takes it legitimate place within the overaching framework provided by transcendental philosophy-and this point of view might find its correlate in the mapping of the regional ontologies developed by the self-explication of the transcendental ego and spelling out the objectivities that the sciences presuppose (Husserl 1960, 62-64, 136-139, 152-157). The main concern of Cairns and Husserl in establishing this framework for the sciences is principally to preserve the integrity of philosophy itself, to prevent its corruption, its reliance on weak bases, and its laxity about its own responsibility to endorse only conclusions that it has tested. One might say that its main concern is a bit defensive, resisting the incursion of psychology upon its own turf.

Of course, Cairns and Husserl also recognize the benefits that situating psychology with reference to a prior transcendental phenomenology can bring. For instance, Cairns (2010, 7f, 26f) argues that Husserlian transcendental phenomenology enables one to recognize that physical reality and psychic reality are mutually heterogenous, thereby undermining the mistaken suppositions on which physicalistic and behaviorist psychologies rest. In addition, Husserl (1970, 298f) himself was clear that the transcendental phenomenology that subjects to critique the unexamined prejudices of the psychological sciences, such as those that result in physicalism and behaviorism, actually bring to realization the very rational ideals of conformity to evidence that have given birth to the enterprise 
of science itself. Transcendental phenomenology aids psychological science, which might be prone to overlook how mental acts are given and to reduce them to mere physical, causally determined processes, in realizing that unprejudiced and evidence-based enterprise that lies at the roots of psychology's own aspirations. Finally, transcendental phenomenology preserves a space within which its claims to truth must be taken on their own terms and not undermined because they are simply the products of material causal processes. By so doing, transcendental phenomenology opens up the possibility that the claims of psychological science itself can find a place within this same space and not be undermined by a self-referential argument. Such an argument, for instance, might assert that scientific acts of knowing are nothing more than the causal products of material processes just like the non-scientific psychological acts that psychological science investigates. As such, it could be argued that scientific acts themselves are relativized to their empirical, material context and are mere responses to physical determinants operating behind the back of psychologists and beneath the threshold of their consciousness. This would be the case, however much those psychologists might pretend that their statements lay claim to an intellectual validity that all other scientists ought to find convincing, regardless of whatever physical processes might be acting on those other scientists.

While transcendental phenomenology can afford these benefits to psychology, they are secondary to the fundamental emphasis characterizing Husserl's and Cairns's philosophical project of demarcating the relations of the sciences to philosophy, namely to ensure that the integrity of philosophy be maintained by not depending on a science outside itself or incorporating within its framework scientific findings that have not been endorsed by the careful appropriation by which philosophy preserves its distinctiveness, autonomy, and eminence.

\section{SCHUTZ / EMBREE ON THE RELATIONSHIP BETWEEN PSYCHOLOGY AND PHILOSOPHY}

Embree (2015, vii) admits from the start that his book Schutzian Theory of the Cultural Sciences is aimed at expounding and advancing Schutz's views on the theory of the cultural sciences, and he contends that the task of a Wissenschaftslehre was fundamental for Schutz as well as Husserl. Embree believes that both of the approached the sciences positively, in contrast to other currents in the phenomenological tradition that approached the sciences more 
defensively. Embree (ib. 5f) differentiates from the beginning the sciencefounding discipline of the positivists (physics), of Husserl (transcendental phenomenology), and of Schutz (a constitutive phenomenology of the natural attitude, or, in other words, a phenomenological psychology).

Following Schutz and providing a framework in which one might situate the science of psychology, Embree (ib. 51, 81) maps out four levels of a hierarchy of thinking that make up a "theory of science", whose fourth level is "philosophical". On the bottom level is everyday, prescientific life in which actors, partners, and observers interpret objects, situations, or the meanings of each other. Above that is the level of "substantive cultural science"2 in which scientists develop empirical or theoretical accounts of common-sense interpretations. On the third level "scientific science theorists" reflect on their work in level two, to examine foundations and improve research and to seek to determine a disciplinary definition, basic concepts, and the methodological procedures of the particular science in which they are involved. Philosophical science theory takes place on the fourth level, and philosophical theorists reflect on the three previous levels and their interrelationships. This final level is widest in scope, but farthest away from the concrete data. Embree asserts that what is distinctive about the fourth, philosophical level is that it takes account of more than one discipline and the work of diverse cultural scientists.

On the bases of this hierarchy of levels, Embree (ib. 106) speculates on possible relationships between philosophers and cultural scientists. Both can meet in the area of methodology on the third level. However, cultural scientists need not understand their own approach philosophically, and an effective cultural scientist need not even have a sophisticated understanding of her methodology. Moreover, a scientific or philosophical understanding of methodology may not be needed for the executing of one's science, and, in fact, too much reflection on methodology can interfere with the pursuit of that science itself. As examples of cultural scientists who do engage in methodological considerations, Embree points to Max Weber and Talcott Parsons, and it is possible for cultural scientists to become philosophers, as occurred with Schutz. Finally, it is conceivable that

\footnotetext{
2 Embree (2015, vii, 17) uses the term "cultural sciences" rather than the term "social sciences", because it includes ethology and recognizes that "culture" is also to be found among non-humans, chimpanzees, for instance, and because Schutz's investigations included history, which is not traditionally conjoined with the social sciences.
} 
philosophers themselves might engage in cultural scientific science to some degree.

Schutz, who described himself as a "sociologically informed philosopher", conceived his own phenomenological psychology in the tradition of Husserl as being foundational for all the other cultural sciences, and thus clearly operating on the fourth of the hierarchic level in a theory of science (ib. 49, 51-53). In addition, from that fourth level, Schutz took account of the methodological reflections that Max Weber and Georg Simmel had already developed for the cultural sciences and that could be located on level three of the science theory, and Schutz attempted to provide more substantial foundations (ib. 51). Insofar as Schutz sought foundations for all the cultural sciences, he was working on a universal, philosophical plane. Of course insofar as Embree describes Weber as working on a foundation for the culture sciences-that is, more than one ${ }^{3}$-there is a sense in which he too worked on the philosophical level, though Weber was impatient with deep-level methodological investigations and often broke them off when he had gone as far as he thought it necessary to go (Schutz 1967, 7). As a result, Schutz (Embree 2015, 52) elucidated many concepts that were nebulous in Weber's work, such as "meaningful action", "subjective meaning", "motivation", "intersubjective understanding", etc.

Given that the philosophical level encompasses the three preceding levels, Embree (ib. 54) is correct in explaining what the basic concepts, distinctive methods, and disciplinary definition would be of Schutz's own phenomenological psychology, which forms the foundation of all the cultural sciences. Consequently, Embree lists several of Schutz's basic concepts, such as "eidos", "empathy", "ego", "inner time", "pre-predicative experience", "intentionality", etc. The distinctive methods of Schutz's phenomenological psychology consist in reflection on intentional experiences and their objects; intentional, genetic, and constitutive analyses; an epoché; and eidetic description. Finally, the disciplinary definition of Schutzian phenomenological psychology indicates that it is not a formal science, but is content-focused, and it concentrates on the meaningfulness of objects, actions, others, precisely the kind of meaningfulness that natural scientific approaches (including behavioristic psychology) abstract from (ib. 55).

\footnotetext{
3 Embree $(2015,79)$ does mention that Parsons and Weber were concerned only with sociology, and as such their reflection on their own science would have exemplified scientific science theory rather than philosophical science theory.
} 
While social psychology makes use of methodological individualism as a means for studying group life, Schutz admits that his phenomenological psychology engages in an artificial abstraction of the individual from society in order to be able to present how meanings and others are constituted (ib. 55f). I would add that Schutz's phenomenological psychology is also eidetic in nature and differs in this way from social psychology that would be focused on empirical cases. Embree (ib. 56) concludes his explanation of Schutz's phenomenological psychology by noting that the question of whether it needs to be grounded in and radicalized by transcendental phenomenology "need not be pursued in the present study"4.

In The Schutzian Theory of the Social Sciences, with this notion of an ultimate, founding philosophy, that is, of a phenomenological psychology, and the four layers of science theory, Embree goes on to treat various cultural sciences and situate them within the framework he establishes. In the first place, Embree (ib. 50) points out that Schutz does not assign the science of psychology itself any place within his classifications, though he does refer to psychoanalysis, behaviorism, and Gestalt theory, and hence his phenomenological psychology, which provides the foundation for the all the cultural sciences represents at the same time his most substantial discussion of psychology, which Embree enhances by discussing its basic concepts, distinctive methods, and disciplinary definition. Embree (ib. 19) shows how economics, like all cultural sciences, must comply with the postulate of subjective interpretation, that is, it must attend to the "subjective" meaning of an (economic) action by an actor, that is, to what the actor means by her action. As result, Schutz's phenomenological psychology, along with ideal-type methodology 5 correlative to it, makes available the conceptual machinery to explain such subjective meaning in economics. Further, the marginal-utility principle defines the discipline of modern economics within the cultural sciences (ib. 22f). Similarly, jurisprudence (ib. 31) depends on a basic norm that defines the domain of legal action and that situates the subjective meaning context of any legal actor. This disciplinary definition, whose basic

\footnotetext{
${ }^{4}$ Embree $(2015,53)$ acknowledges that transcendental phenomenology has opened up questions useful for the cultural sciences and, with phenomenological psychology, has answered many of them, but Schutz did not find it necessary to work on the transcendental level other than in his clarification of the structures of consciousness in the Phenomenology of the Social World, part 2.

${ }^{5}$ For instance, Weber's construction of the Protestant in The Protestant Ethic and the Spirit of Capitalism is based on an ideal type of the Protestant in which Weber attempts to construct the motives and purposes, that is, the meaning of economic actions of the Protestant as economic actors.
} 
concepts can draw on the concepts of subjective meaning that Schutz's phenomenological psychological affords, also ends up resorting to the methods of ideal type construction (explaining the motives of legal actors) and insider/outsider (or subjective/objective meaning) in order to explain interactions within a legal framework. Embree (ib. 69f) demonstrates how cultural anthropology, which addresses the collective cultural patterns of primitive group life, would not constitute a psychological science whose focus would be on individual lives, though its basic concepts would have to draw on the foundational concepts Schutz develops about intersubjective meaning interpretation in his phenomenological psychology. Finally, Embree (ib. 42) examines sociology, which for Schutz would have been defined as a discipline in terms of investigating contemporaries and of beginning with social groups to which individuals belong or with individuals relating to others in such groups. While Schutz tended to assimilate sociology with the social psychology (ib. 38, 42-45), which his own cultural scientific essays "The Stranger" and "The Homecomer" instantiate in an exemplary manner, he did recognize that in the United States sociology and social psychology could be separated. However, insofar as sociology would presuppose intersubjective meaning interpretation, Schutz's own foundational phenomeno-logical psychology, which he later described as a social psychology, offered the (eidetic) basic concepts that any sociology could deploy and that he masterfully employed in his own cultural scientific works on the stranger and the homecomer (ib. 42-45).

This quick recapitulation of Embree's Wissenschaftslehre makes it apparent that when it comes to disciplinary definition, one of the tasks engaged in at level three of the science theory hierarchy, such as the definition of the field of economics as marked out by the marginal utility theory or jurisprudence in terms of a basic legal norm-as Hans Kelsen suggested (ib. 27)-, self-reflective practitioners of those sciences and philosophers could collaborate together and converge in their findings. As regards the methodology that science theorists may try to elucidate, one could imagine diverse methodologies (e.g. statistics) on which their sciences might rely, but Embree with Schutz repeatedly suggests that all the cultural sciences, if they are going to take account of the subjective meaning of actors, must always be able to resort to ideal-type construction as a basic methodology. Indeed, Schutz $(1964,84 f)$ himself insists that all generalizations and idealizations in the social sciences must be able to be traced back to the subjective meanings of individual actors, able to be captured in ideal types, 
since such actors interpret their world in the way that the objects of the natural sciences, such as electrons or molecules do not. This necessity of the cultural sciences to be able to revert to type construction reflects the deeper reality that actors interpret their relationship to the world and each other and that this deeper reality is what Schutz's phenomenological psychology expounds in its fullness. Consequently, it is no wonder that when Embree takes up the third component of layer three of science theory reflection, basic concepts, he recommends all the categories relevant for the interpretation of subjective meaning in the social world spelled out in Schutz's phenomenological psychology. While science theorists within a specific science and in collaboration with philosophers are able to articulate the definitions of their distinctive disciplines, the identification of the importance of ideal-typical methodology for all the cultural sciences and the relevance of Schutzian phenomenological psychology for the basic concepts of all the cultural sciences indicates the foundational, philosophical nature of Schutz's science theory, which crosses the boundaries of all the cultural sciences.

Given that Embree envisions Schutz's phenomenological psychology as furnishing basic concepts to all the cultural sciences, which all engage in the subjective interpretation of meaning for which the ideal-type methodology is most apt, one can understand why Embree repeatedly insists that Schutz not be classified as phenomenological sociologist. Embree (2015, 78, 159) explain that few of Schutz's works are sociological and even those few are more socialpsychological in nature (ib. 78, 159). In addition, Embree suggests that Schutz strives to articulate a theory that reaches beyond sociology insofar as he identifies himself as a "sociologically sophisticated philosopher" rather than a philosophically sophisticated sociologist (ib. 78) and insofar as Schutz's interests extend to other sciences besides sociology to the point that his account of economics is more thorough than his account of sociology (ib. 90). A further danger of identifying Schutz's work with phenomenological sociology is that it might discourage psychology, psychotherapy, and similar sciences from mining the resources of Schutz's theory for their own sciences. This is especially so if Schutz is mistakenly taken to be basically concerned with social groups instead of interpretive relations between individuals that eventually result in collectivities (ib. 94s). Immediately after this comment, Embree proceeds to list the basic concepts that psychotherapy would use and then to itemize Schutzian basic concepts about intersubjective meaning interpretation that would also be of value 
for psychotherapy as a science. Clearly, the point seems to be to refuse to identify Schutz's work with sociology in order to make its resources available to the broad spectrum of the cultural sciences. It should be added, however, that at one point Embree (ib. 42) admits that Schutz characterized his own phenomenological psychology as a "social psychology" and that he considered sociology as not being distinguished from social psychology in much the same way that sociologists today view social psychology as a part of sociology. Given these complex relationships, it is understandable why many might consider Schutz a social psychologist.

4. Cairns / husserl Versus Embree / Schutz on the Relationship betWeen PHENOMENOLOGY AND PSYCHOLOGY

Although both Cairns/Husserl and Embree/Schutz are deeply interested in a Wissenschaftslehre that articulates the relationship between phenomenology and psychology, their emphases are quite different. First of all, the principal concern of Cairns and Husserl as he reads him is for philosophy itself, what one's hopes are for philosophy. Given that phenomenology as philosophy and psychology were blended in Husserl's early writings, particularly in the Logical Investigations in which a non-psychologistic logic was presented as relying on an introspective descriptive psychology, both Cairns and Husserl initiated a reform that began in Ideas 1 and culminated in Formal and Transcendental Logic and Cartesian Meditations, as Cairns tells the story. The point was to establish the autonomy of phenomenology as a philosophy over against psychology. This autonomy was to be achieved in three ways. First of all, there was a need to separate psychology from phenomenology. It was not enough to establish the independence of the objects of cognition, such as the rules of logic, from the underlying material conditions that might relativize them, but also the acts through which such objects were known needed to be known independently of the material conditions through which a descriptive psychology might explain those acts. Even efforts to engage in a pure psychology focused on inner processes eidetically analyzed (e.g., in Philosophy as Rigorous Science) would nevertheless fail to escape unexamined presuppositions about worldliness on which such a psychology would rely. It was of importance then to separate phenomenology as philosophy from psychology, as the phenomenological reduction did, establishing on the basis of 
the reduction a transcendental phenomenological sphere over against psychology conducted within the natural attitude. The separation, the first step toward establishing phenomenological, philosophical autonomy further enhances the autonomy of philosophy in two ways. It eliminates the danger of philosophy and phenomenology being undermined because reliant on and relativized to the current state of psychological science, which, were it to be altered, would undo the philosophy based upon it. In addition, this separation between phenomenology and psychology ensure that striving for philosophical responsibility, that refusal to take over without critical examination, any of the claims of psychology, in particular about psychic acts, unless the philosopher can see for herself that such claims are supported by the evidential having of what is claimed.

By contrast, the Embree/Schutz paradigm shows little interest in upholding the autonomy of philosophy or phenomenology that is to be separated from psychology and stand over against it. In the first place, Embree, following Schutz, seems quite content with having a distinctive phenomenological psychology, or a constitutive phenomenology of the natural attitude, as itself the philosophical foundation for the cultural sciences. As Embree observes, Schutz provides no other place for a separate science of psychology in his Wissenschaftslehre, although were he to determine a niche for psychology, it would no doubt be a kind of cultural science like psychotherapy and would probably rely on the basic concepts and methodology of ideal type construction that Schutz sees as foundational for all the cultural science.

Instead of protecting the autonomy of philosophy/phenomenology over against the cultural sciences (among which we might locate the contemporary science of psychology), Embree and Schutz conceive of a much more cooperative relationship. In the first place, Embree $(2015,79)$ denominates his own science theory as a theory of cultural science rather than philosophy of cultural science because Schutz recognizes that social scientists also are accustomed to reflect in illuminating way on the basic concepts and methodologies of their particular science. Despite this convergence between self-reflective cultural scientists and philosophy, Embree (ib.) also allows for an implicit distinction between scientific and philosophical science theory insofar as he does distinguish these two types of science theory by situating them on the separate third and fourth rungs of the hierarchy of science theory and insofar as he admits that philosophical science theory seeks to spell out foundational basic concepts and methodologies for 
several sciences (e.g. the cultural sciences) as opposed to scientific science theories that limit themselves to their own disciplines. However, the convergence between philosophy and the cultural sciences can be further seen since Embree argues that on level three of the hierarchy scientific science theorists of the cultural sciences have defined their disciplines in a way that philosophers can find to be effective and acceptable. For instance, economists claim that the principle of marginal utility specifies their area of investigation, or Hans Kelsen presents the basic norm of law as marking out the field of jurisprudence. Philosophers can also build on, develop, or even correct the basic concepts and methodological processes that scientific science theorists, such as Weber and Parsons, laboring on level three, have articulated for their own particular sciences. Indeed, The Phenomenology of the Social World represents an effort on the part of Schutz, on the same level with Weber, as it were, to refine the unclarified basic concepts that Weber proffered. In addition, repeatedly Embree lists the basic concepts of various sciences, such as psychotherapy, and then suggests that how supplementary basic concepts and ideal-typical methodology derivative from Schutz's phenomenological psychology can assist these cultural sciences in presenting the intersubjective meaning interpretation that lies at the basis of all these cultural sciences. Even statistical versions of the cultural sciences would presuppose the subjective meaning of actors that can be conveyed through Schutzian basic concepts and the ideal typical methodology. Finally, not only does Embree (ib.) conceive Schutzian phenomenology as cooperating with the scientific science theorists of the cultural sciences, but he even adds that higher level reflections of methodologists, such as those undertaken by scientific science and philosophical science theorists, need to learn from those engaged in substantive science, as Schutz (1996: 146) stated in a letter to Adolf Lowe:

It is my conviction that methodologists have neither the job nor the authority to prescribe to social scientists what they have to do. Humbly, he has to learn from social scientists and to interpret for them what they are doing. It seems to me that all the great masters of our social sciences proceeded as I have outline in my general scheme.

The emphasis in Embree's philosophical science theory shows little concern about the autonomy of philosophy, as one finds in the Cairns/Husserl framework; instead, the focus seems to be much more cooperative, with Embree's theory 
respecting the discipline-defining reflections of cultural scientists, supplementing their work with basic concepts and methodological processes applicable to all the cultural sciences, and even learning from those engaging in substantive science.

There is, of course, one point at which Embree's philosophical science theory seeks to separate itself from an identification with a particular science that might parallel Cairns's insistence that philosophy distance itself from psychology. That point occurs when Embree asserts that Schutz's philosophical work not be identified with phenomenological sociology from which it differs. However, Embree's interest is not in protecting the autonomy of Schutz's philosophical position, but rather in making sure that the resources of Schutz's foundational phenomenological psychology be available to sciences such as psychology and psychotherapy, whose principle concentration might be on the interpretive activity of individuals instead of the social groups that sociology investigates, though sociology itself can also draw on the basic concepts and methodological processes spelled out in Schutz's phenomenological psychology. In a sense, Embree separates philosophy from (phenomenological) sociology not to protect philosophy's autonomy but to ensure that it be better "marketed" for the broad spectrum of cultural sciences beyond sociology.

Although I have depicted Cairns and Husserl construing the relationship between philosophy and psychology as emphasizing the protection of philosophy's autonomy and its distinctness from psychology, it should not be overlooked that preserving such autonomy results in benefits for psychology also. By separating transcendental phenomenology from psychology one avoids the psychologism that Husserl opposed in the Logical Investigations and thereby sustains the rules of logic without which psychology and any scientific explanation would become meaningless. Furthermore, transcendental phenomenology provides for a sphere in which the material, causal conditions that the sciences study will not undermine the conscious processes on which science itself depends. In addition, as we have seen, transcendental phenomenology completes the trajectory toward rationality that science itself began insofar as it does not leave unattended or forgotten the consciousness of the scientist that science may have explained away and insofar as it thereby reverses the crisis of the European sciences. Finally, Husserlian transcendental phenomenology defends psychology itself against any collapsing of the eidetically defined psychical world into the physical reality and against the behaviorism resulted from such a de-diffe- 
rentiation of domains. In this resistance to behaviorism, the Cairns/Husserl paradigm converges with the Embree/Schutz (Embree 2015, 21, 37, 55; Schutz $1962,53,58 f)$ perspective that articulates first of all what social reality is, namely a world in which actors interpret their world, and that explains how this reality therefore requires a distinctive methodology (type-construction) to take account of actors' subjective meaning, as opposed to the world that the natural sciences investigate in which molecules and electrons do not interpret their world and the (natural) scientists are the only world-interpreters. Behaviorism results when one applies the methodology of the natural sciences to the social world, without first considering the nature of that social world and the methodology appropriate to it. To conclude, because of the historical entanglement of philosophy and psychology, Cairns and Husserl emphasize the importance of disentangling them and supporting the autonomy of phenomenology/philosophy, and this disengagement eventually redounds to the advantage of both philosophy and psychology. By contrast, the Embree/Schutz philosophical theory of science lacks any such emphasis on philosophical autonomy and seems rather disposed to collaborate from the start with the cultural sciences to which it is related, making available the basic concepts and correlative methodological procedures needed for the intersubjective meaning interpretation that lies at the root of these sciences.

This tension between transcendental phenomenology and phenomenological psychology as diverse foundational strategies for accommodating psychology and/or the cultural sciences is played out in the dialogue between Cairns and Embree/Schutz that I have constructed in this essay. The tension had already appeared in Edmund Hussserl's "Nachwort zu meinen Ideen" that Schutz (1967, 43f) appealed to in order to justify his Phenomenology of the Social World as a phenomenological psychology or constitutive phenomenology of the natural attitude. As one might expect, in that essay Husserl (1952, 140), like Cairns, opposes from the start the psychologism or transcendental anthropologism that occurs when one grounds philosophy on psychology or anthropology and that results from not having reach the specific ground of philosophy by entering the transcendental sphere through the phenomenological reduction. After stressing the intuitional rather than deductive character of transcendental phenomenology, he (ib. 144) contrasts descriptive psychology with transcendental phenomenology, which depends on an attitudinal alteration out of or away from the natural 
attitude in which on lives among others in the usual sense. But at this point, Husserl (ib.) explains how as a psychologist one could remain within the natural attitude and describe carefully one's inner experience, one's psychic life, through account that remain true to what is given in intuition and hence for that reason are often called "phenomenological". Such a "phenomenological psychology" must concern itself with the invariant features of a community of psychic life. Husserl (ib.) hypothesizes that such a psychology could become a great, selfstanding science (eine grosse eigenstandige Wissenschaft). Although Husserl (ib. 155f, 159) later criticizes the phenomenological psychologies developed by Franz Brentano and John Locke, his early description of phenomenological psychology is, in general, quite positive, and it is clear why Schutz would be quite willing to claim the title of phenomenological psychology for his own work. However, immediately after this brief interlude on phenomenological psychology, Husserl (ib. 143, 148, 153, 160, 162) proceeds to heap praise on transcendental phenomenology that prescinds from the being-meaning of whatever it analyzes, possesses a higher dignity than other sciences and forms of phenomenology, exhibits exemplary philosophical responsibility, constitutes an ultimate point of view to which the world is relative, must comport itself with autonomy, and radically submits every presupposition to examination. Husserl (ib. 148, 160) even argues that when one fails to arrive at the transcendental level one's work is "unphilosophical". While Embree/Schutz would no doubt bristle at the criticism that their work is not even philosophical, they were able to find a distinctive place in the phenomenological panorama in which they could make positive, collaborative contributions to the cultural sciences.

\section{WORKS CITED}

CAIRNS, Dorion (1975). "A Letter to John Wild about Husserl", Research in Phenomenology, Vol. 5: 155-181.

-, (2002a). "The Fundamental Philosophical Significance of Husserl's Logische Untersuchungen", Ed. L. Embree / F. Kersten / R. Zaner, Husserl Studies, Vol. 18, 1: 41-49.

—, (2002b). "Phenomenology and Present-Day Psychology", Phenomenology and the Cognitive Sciences, Vol. 1, 1: 69-77. 
-, (2004). "An Approach to Husserlian Phenomenology", in Phenomenology: Critical Concepts in Philosophy, Vol. 1: Phenomenology: Central Tendencies and Concepts, Ed. Dermot Moran and Lester E. Embree, with the assistance of Tanja Staehler and Elizabeth A. Behnke, London/New York: Routledge, pp. 25-37.

-, (2007). "Husserlian Phenomenology and Objectivism", Journal of the BritishSociety for Phenomenology, Vol. 38, 2: 116-127.

—, (2010). "Nine Fragments on Psychological Phenomenology", Ed. Lester Embree / Fred Kersten / Richard M. Zaner, Journal of Phenomenological Psychology, Vol. 41, 1: 1-27.

-, (2013). The Philosophy of Edmund Husserl, Ed. L. Embree, Dordrecht: Springer.

EMBreE, Lester (2003). Reflective Analysis: A First Introduction into Phenomenological Investigation, Morelia: Jitanjáfora.

-, (2012). Animism, Adumbration, Willing, and Wisdom: Studies in the Phenomenology of Dorion Cairns, Bucharest: Zetabooks.

-, (2015). The Schutzian Theory of the Cultural Sciences, Dordrecht: Springer.

HUSSERL, Edmund (1952). "Nachwort", in Ideen zu einer reinen Phänomenologie und phänomenologischen Philosophie. Vol. 3: Die Phänomenologie und die Fundamente der Wissenschaften, Ed. Marly Biemel, The Hague: Martinus Nijhoff.

-, (1960). Cartesian Meditations: An Introduction to Phenomenology, Trans. Dorion Cairs, The Hague: Martinus Nijhoff.

-, (1970). "The Vienna Lecture", in The Crisis of European Sciences and Transcendental Phenomenology: An Introduction to Phenomenological Philosophy, Trans. David Carr, Evanston: Northwestern University Press, pp. 269-299.

-, (2001). Logical Investigations, Trans. J. N. Findlay, Ed. D. Moran, London/New York: Routledge.

ScHUTZ, Alfred (1962). "Concept and Theory Formation in the Social Sciences", in Collected Papers, Vol. 1: The Problem of Social Reality, Ed. Maurice Natanson, The Hague: Martinus Nijhoff, pp. 48-66. 
-, (1964). "The Problem of Rationality in the Social World", in Collected Papers, Vol. 2: Studies in Social Theory, Ed. Arvid Brodersen, The Hague: Martinus Nijhoff, pp. 64-88.

-, (1967). The Phenomenology of the Social World, Trans. George Walsh / Frederick Lehnert, Evanston: Northwestern University Press.

-, (1996). "Social Science and the Social World", in Collected Papers, Vol. 4., Ed. w. preface and notes by Helmut Wagner and George Psathas, in collaboration with Fred Kersten, Dordrecht: Kluwer Academic Publishers, pp. $140-146$. 